\title{
ENCARCERAMENTO EM MASSA E O MITO DA DEMOCRACIA RACIAL: A INTERLIGAÇÃO DE UM FENÔMENO CRESCENTE NO BRASIL ${ }^{1}$
}

MASS INCARCERATION AND THE MYTH OF RACIAL DEMOCRACY: THE INTERCONNECTION OF A GROWING PHENOMENON IN BRAZIL

Letícia Dias CORRÊA ${ }^{2}$

Clóvis Alberto VOLPE FILHO

ISSUE DOI: $10.21207 / 2675-0104.2019 .908$

\section{RESUMO}

O sistema carcerário brasileiro ocupa hoje seu terceiro lugar no ranking mundial de encarceramento, perdendo apenas para China e Estados Unidos. A maioria dos componentes deste sistema são homens e mulheres negros na faixa etária dos 18 aos 29 anos. Essas duas informações compõe a base deste artigo, um resumo da monografia apresentada no Programa de Iniciação Cientifica 2018/2019 da Faculdade de Direito de Franca. O artigo visa questionar a ligação desses dados, visto nos encontrarmos

\footnotetext{
${ }^{1} \mathrm{O}$ presente artigo sintetiza a monografia de conclusão da pesquisa, realizada para o Programa Interno de Bolsas de Iniciação Científica (PIBIC 2018-2019) da Faculdade de Direito de Franca (FDF), Franca/SP.

${ }^{2}$ Discente da Faculdade de Direito de Franca (FDF), Franca/SP. Bolsista do Programa Interno de Bolsas de Iniciação Científica (PIBIC 2018-2019).

3 Possui graduação em Direito pela Faculdade de Direito de Franca (2003), mestrado em Direito Constitucional pela Universidade de Franca (2005), especialização em Ciências Criminais pela Puc-Minas (2011) e MBA em Direito Empresarial pela FGV (2011). É doutor em Direito Constitucional pela Fadisp, advogado e professor da graduação da Fafram/Ituverava e da Faculdade de Direito de Franca. Tem experiência na área de Direito, com ênfase em Direito Constitucional, Direito Penal e Direito Processual Penal. Foi pesquisador/bolsista durante a graduação pela Fapesp, e durante o mestrado pesquisador/bolsista pela Capes.
} 
em uma sociedade majoritariamente negra em que seus membros creem na existência do racismo, bem como acreditam numa democracia racial, fatos totalmente controversos entre si.

Palavras-chave: Cárcere, Encarceramento em massa, Racismo.

\section{ABSTRACT}

The brazilian prison system today occupies its third place in the world ranking of incarceration, losing only to China and the United States. Most of the components of this system are black males and females aged 18 to 29 years. These two information compose the basis of this article, a summary of the monograph presented in the Scientific Initiation Program 2018/2019 of the Faculty of Law of Franca, which seeks to question the connection of these data, as we meet in a society Mostly black in which its members believe in the existence of racism, as well as believing in a racial democracy, totally controversial facts.

Keywords: Prison, Mass incarceration, Racism.

\section{INTRODUÇÃO}

O presente trabalho está inserido na área da Criminologia Crítica e trata da íntima correlação entre a crença em uma suposta democracia racial brasileira e o encarceramento em massa, também presente no país, que tem como principal "expoente" a população negra.

É tido como principal objetivo analisar as interligações entre o cárcere e a população afrodescendente como vulnerável dentro deste panorama e suas consequências, buscando abordar, brevemente, o conceito de punir e questionar de maneira ampla, distante do senso comum e midiático, a forma natural que a sociedade aceita a ocorrência deste fenômeno.

Aborda-se o tema partindo do princípio de que mesmo com o passar dos séculos e significantes avanços sociais, que permitiram à população negra brasileira a conquista da abolição da escravatura em 1888, a legislação brasileira não pôde e nem detém de poderes suficientes para transformar a ideologia racista que estrutura a coletividade nacional.

Seguindo tal linearidade de pensamento, fica evidente que não é possível analisar por completo as questões de raça e classe no Brasil sem uma detalhada análise de sua estrutura histórica, que se inicia na colonização e na escravidão do povo negro sob o branco, ou seja, para uma efetiva discussão de questões socialmente relevantes para o país é necessário um recorte racial, como o proposto neste artigo. 
Produto de mais de trezentos anos de escravização e controle, de uma supremacia branca sobre os negros, o racismo estrutural brasileiro não é surpresa e ainda se faz presente em nossa atual conjuntura. Entretanto, devido à grande miscigenação e políticas de branqueamento da população negra após a abolição, muitos brasileiros acreditam que exista uma democracia racial no país, baseados no fato de o mesmo ter deixado de ser escravocrata oficialmente em 1888 com a assinatura da Lei Áurea.

Por mais que a norma trouxesse liberdade e aspiração de uma nova vida aos ex-escravos, a grande maioria estava alheia à sua situação política, devido ao fato de serem, com raríssimas exceções, analfabetos, dado que a filosofia da escravidão fazia com que os mesmos não fossem estimulados a pensar ou agir. Portanto, os negros não possuíam condições de se igualarem no mercado de trabalho, por serem considerados seres inferiores e sem qualificação alguma em conseguir um emprego dignamente favorável a eles.

A liberdade deixou clara a ausência de uma plena obtenção de direitos aos negros que não obtiveram orientação alguma para se integrar em uma sociedade assalariada. O negro, descartado pelo governo, substituído nas lavouras de maneira fácil e rápida pelas campanhas de imigração, viu-se marginalizado e à mercê da sorte para traçar uma nova vida. Assim, passou a ocupar os locais mais afastados do centro e a se marginalizar.

Além disso, havia em curso no país a construção de uma identidade nacional brasileira, que se inicia a partir de meados do século XIX, em um Brasil já republicano. É nesse contexto que a ideia de raça aparece como um fator crucial de desenvolvimento, haja vista que a maioria da população era formada por ex-cativos e seus descendentes, um dos principais fatores de atraso e, portanto, impensável para uma nação que reverenciava suas "raízes europeias" e buscava ascensão.

Nina Rodrigues foi o primeiro grande cientista brasileiro a incorporar as teses racistas no Brasil moderno, buscando provar em sua obra "As Raças Humanas e a Responsabilidade Penal” a degenerescência e tendências ao crime dos negros e mestiços.

Apesar de grande expoente do racismo estrutural e pseudocientífico no país, Nina representava uma corrente segregacionista na busca de uma identidade brasileira, o que não cativou inteiramente a elite. Com efeito, havia uma segunda corrente, a embranquecedora, que apostava suas fichas na miscigenação como a salvação do país: uma esperança que consistia na construção de uma nação formada por um povo 
superior, aos moldes europeus e não degenerados como os negros de pele escura.

Deste conjunto histórico, nasce a obra "Casa Grande \& Senzala" de Gilberto Freyre, transformando o funcionamento da dinâmica racial no país. Seu livro seria uma reconstrução fantasiosa do passado nacional, criando uma ideologia de falsa ilusão, definida pela ausência de preconceito, bem como discriminação e, consequentemente, pela existência de oportunidades econômicas e sociais iguais para pessoas negras e não-negras no Brasil.

O mito da democracia racial serviria para dar fim a um possível conflito entre raças, cegando os indivíduos negros com uma falsa impressão de que faziam parte da comunidade nacional, enquanto a estrutura de privilégios, que historicamente os descriminou, era mantida.

O mito de democracia racial, baseado na dupla mestiçagem biológica e cultural entre as três raças originárias, tem uma penetração muito profunda na sociedade brasileira: exalta a ideia de convivência harmoniosa entre os indivíduos de todas as camadas sociais e grupos étnicos, permitindo às elites dominantes dissimular as desigualdades e impedindo os membros das comunidades nãobrancas de terem consciência dos sutis mecanismos de exclusão da qual são vítimas na sociedade. Ou seja, encobre os conflitos raciais, possibilitando a todos se reconhecerem como brasileiros e afastando das comunidades subalternas a tomada de consciência de suas características culturais que teriam contribuído para a construção e expressão de uma identidade própria. Essas características são símbolos nacionais pelas elites dirigentes. (MUNANGA 1999, p.80)

Como expõe a citação acima, não foi possível, aos negros e pardos, desfrutar da autonomia social, o que gerou a falta de democratização do poder. Isso nos ajuda a compreender o porquê de, mesmo sendo maioria percentual no país, os não-brancos ainda são tidos como uma minoria carente de políticas públicas e necessitados de ações afirmativas, buscando o mínimo de respeito e igualdade.

Desse modo, o racismo frequentemente se manifesta de maneira irrefletida, como se consolidou no exemplo dado. Mesmo quando não se trata de escondê-lo intencionalmente, a falta de consciência do ator se revela em suas atitudes.

É por isso que a democracia racial é tida como mitológica, pois é uma narrativa imaginada que evolui com as condições históricas e culturais, procurando demonstrar a origem das coisas. É um mito, pois é a criação e naturalização de uma falsa realidade que permite com que toda 
uma nação acredite que as questões raciais foram superadas pela simples e rasa ocorrência da "mistura" das diversas raças que compõem nosso país. Assiduamente impedindo-nos de abordar assuntos profundos sobre tais questões, visto a negação do povo brasileiro e sua dificuldade em se identificar com certa raça ou grupo racial, bem como possível e potencial autor de discriminações.

Mais um fato relevante que contribuiu com o enraizamento desta falsa democracia foi a construção da identidade branca consolidada em uma imposição da supremacia por parte dos colonizadores, fundada nas teorias racistas científicas que buscaram, a todo preço, justificar tal exploração. Esse processo atribuiu privilégio e poder à identidade branca, tomando-a como parâmetro para julgar os demais grupos.

Conforme explica o professor Silvio Almeida (2019, p.32-34), o racismo "é uma forma sistemática de discriminação que tem a raça como fundamento, e que se manifesta por meio de práticas conscientes ou inconscientes que culminam em desvantagens ou privilégios para indivíduos, a depender do grupo racial ao qual pertençam”. E, devido a isso, é um processo em que condições de subalternidade e de privilégio se distribuem entre grupos raciais e se reproduzem nos âmbitos da política, da economia e das relações cotidianas. Portanto, racismo não é delimitado a um mero ato ou atos discriminatórios, como a democracia racial supõe.

É muito comum que o brasileiro médio veja o racismo somente como um ato discriminatório individualizado, um possível desvio de caráter, como jogar banana em um negro e chamá-lo de "macaco" ou se recusar a atender uma pessoa negra em certo estabelecimento pelo fato da mesma ser negra, por exemplo. O racismo pode ser materializado por um ato discriminatório, porém é um processo muito mais complexo, envolto em facetas institucionais e estruturais.

Institucional, pois seria produto das instituições administradas pela parte dominante - Estado, Legislativo, Judiciário, escolas, Igreja etc da sociedade, fazendo prosperar desvantagens e privilégios sob uma ótica racial. Assim, os "conflitos raciais" também seriam parte das instituições, porém, como explica o professor, o racismo institucional é apenas a reprodução do racismo estrutural, visto que as instituições são formadas, antes de tudo, por membros sociais reprodutores e condicionados a uma estrutura social pré-existente.

A partir daqui é possível compreender que as raízes históricas e estruturais racistas se mantêm devido à política, que é a principal engrenagem deste sistema. Esse poder, desde sempre, esteve retido em 
mãos privilegiadas racialmente: as brancas. Estes, no que lhes dizem respeito, ocuparam um lócus social de favorecimento onde seus ocupantes formam "o topo da cadeia", em que o saldo dessa posição é o acesso a recursos materiais ou não, sobre os desfavorecidos. A esse local dá-se o nome de branquitude.

Quem ocupa essa posição se vê isenta de discussões raciais por não ser visto como um ser de cor, mas como normativa, como o "comum", delegando o debate e a discussão ao outro racializado. É por isso que o fato de os negros serem maioria populacional, as maiores vítimas da violência policial, não ocuparem cargos de destaque social, ganharem menos que pessoas brancas, serem a maioria massiva em estabelecimentos prisionais, entre outras considerações, não traz revolta, reflexões ou questionamentos, pois acredita-se que esses fatores são puramente políticos e não devem ser analisados sob óticas raciais (SCHUCMAN, 2012, p.XX).

\section{O CÁRCERE, A SOCIEDADE E O NEGRO}

\section{1}

\section{BREVE DISCUSSÃO ACERCA DO CONCEITO DE PUNIR}

Neste cenário, a produção sócio-antropológica, por meio do racismo científico, passou a justificar o colonialismo e a superioridade dos colonizadores - e, consequente inferiorização do negro - em um mundo pós-escravidão.

Em 1890 nasce nosso Código Penal que recebeu grande influência europeia para se constituir, em especial da Itália, sob os preceitos criminológicos da Escola Positivista, que possuía como principal expoente Cesare Lombroso, influenciador direto de Nina Rodrigues. O professor e psiquiatra, dedicado a pesquisar a relação entre a demência e a delinquência, em uma de suas principais obras "O homem delinquente", compartilha com o mundo a sua teoria do delinquente nato, marcando o nascimento da Criminologia como ciência na forma do paradigma etiológico.

Segundo sua teoria, a causa do crime estaria presente na genealogia e essência do próprio delinquente, ou seja, ele seria instintivamente predestinado a cometer delitos. Seu método de pesquisa foi baseado em uma simples comparação, analisando grupos de não 
criminosos com criminosos em prisões e hospícios. Além disso, individualizou os criminosos com certas anomalias (anatômicas e fisiológicas) que definiam o tipo antropológico do delinquente (LOMBROSO, 2007, p.195).

Para a nova legislação penal, a teoria do criminoso nato, promotora de estereótipos físicos que facilitavam a identificação dos criminosos, adequou-se perfeitamente às necessidades das elites nacionais que possuíam voz ativa e participante no governo. Desse modo, os criminosos natos do Brasil na época possuíam particularidades em comum, a mais marcante delas era sua cor: a pele negra.

Não tão distante ou dessemelhante daquele século, a crise da segurança pública ainda nos assola, porém, o medo atual é, além das características dos criminosos, da violência amplamente divulgada e da insegurança que esta gera. Hoje a população manipulada pelos meios de comunicação e seus quadros criminais informativos, consome um espetáculo medonho e questionável, onde as vítimas e os agentes das tragédias são expostos de uma maneira claramente antidemocrática aos mais diversos tipos de pré-julgamentos, visando sua condenação sem qualquer direito a defesa, contrariando, assim, todas as regras basilares de um Estado Democrático, em especial a da presunção da inocência, de máximas garantias e o da liberdade.

Essa ampla divulgação e exposição da violência contribuem como fator alienante ao cidadão comum que chega a crer que o Brasil é um país que não pune ou que pune pouco os criminosos sanguinários retratados diariamente. Essa chamada de "massificação do direito de punir" tem fator alienante, pois o nosso país é o terceiro que mais encarcera no mundo, e o debate social que deveria ser tratado dentro deste contexto não é, por exemplo, o da redução da maioridade penal, mas, sim, questionar se este sistema penal encarcerador e punitivo existente há décadas efetivamente funciona num país violento, inseguro e, novamente, encarcerador.

Portanto, o que observamos acontecer nas prisões atuais nada mais é do que um reflexo cultural e histórico, que trata o cárcere apenas como um local de punição e de afastamento do indivíduo "problemático" da sociedade, focando em sua função retributiva, e não na restaurativa. A questão punitiva e sua problemática não podem, de maneira alguma, ser tratadas de uma maneira policialesca, sem a premissa primordial de que todo cidadão, no âmbito de qualquer processo penal, é um ser munido de direitos fundamentais, e que incutir a ideia de que uma lei forte, de máxima penalização e mínimas garantias processuais, irá solucionar problemas 
sociais e de violência que atingem nosso país de maneira estrutural, gerando, no seio social, uma falsa impressão de segurança, dando um efeito falso a verdadeira função do nosso Direito Penal e Processual Penal.

3.2 Guerra às drogas e sua função não declarada no encarceramento A Lei de Drogas, de 2006, foi instituída substituindo o texto de 1976, trazendo uma inovação: a distinção entre usuário e traficante. Os crimes definidos pela lei também diferem a posse para uso pessoal, que é considerada um delito de mero potencial ofensivo, enquanto o tráfico de drogas é equiparado a crimes hediondos ${ }^{4}$, tendo seu regime inicial fechado, onde a pena mínima é de cinco a quinze anos de prisão. Enquanto o delito de mero potencial ofensivo prevê uma pena mais branda, como: advertência, prestação de serviços à comunidade ou obrigação de cumprir medidas educativas.

Porém, divergente do que se presume, a distinção entre esses dois agentes tão diversos no universo da guerra às drogas não é óbvia, pois, por exemplo, a lei determina que "o juiz atenderá à natureza e à quantidade da substância apreendida, ao local e às condições em que se desenvolveu a ação, às circunstâncias sociais e pessoais, bem como à conduta e aos antecedentes do agente ${ }^{5}$ " para definir se a droga se destinava ao consumo pessoal do agente abordado, e é aqui que podemos enquadrar sua relação com o encarceramento massivo.

Tal critério é nitidamente subjetivo, pois a atuação dos agentes policiais e judiciais utilizam arbitrariamente as condições pessoais, o local e os antecedentes para a classificação da conduta. Dessa forma, o estereótipo do traficante de drogas, produzido pelo próprio sistema punitivo, funciona como o elemento central de enquadramento da conduta típica, tornando essa diferenciação circunstancial (ZACCONE, 2004).

Além disso, é comum que os órgãos persecutórios não investiguem tais condutas de modo aprofundado, apresentando acusações com frágil conjunto probatório, munido, apenas, do depoimento dos policiais que efetuaram as prisões em flagrante. Por sua vez, o Poder Judiciário supre a precariedade das acusações com o arbitrário julgamento com base no estereótipo - institucional - do acusado, enquanto o "traficante empresário", que lucra e investe no mercado de drogas a partir

${ }^{4}$ Lei $\mathrm{n}^{\mathrm{o}} 8.072$, de 25 de julho de 1990

${ }^{5}$ Art.28, $\S 2^{\circ}$ da Lei ${ }^{\circ} 11.343$, de 23 de agosto de 2006 
de operações financeiras e logísticas, encontra-se quase que invulnerável ao sistema penal, tendo em vista sua seletividade (SHIMIZU, CACIEDO, 2016).

Outra grande contribuição ao encarceramento e erro grave da Lei de Drogas é a equiparação do tráfico com os crimes hediondos, provocando um indevido engessamento da atuação jurisdicional ao não permitir que o aplicador da lei haja de maneira proporcional, criteriosa e, até mesmo, segundo as características pessoais do indivíduo. Em uma tentativa de amenizar o equívoco, criou-se a possibilidade de diminuir a pena do agente de $1 / 6$ a $2 / 3$, com o $\$ 4^{\circ}$ do art. 33 da Lei de Drogas, o chamado "tráfico privilegiado", que deve ser aplicado ao réu "primário, de bons antecedentes, que não se dedique às atividades criminosas nem integre organizações criminosas", alternativa esta que, recentemente, segundo o STF, não deve ser considerada como crime hediondo.

Hoje, em nosso país, as prisões por tráfico de drogas correspondem, em relação aos homens, por $29,26 \%$ e 64,48\% em relação às mulheres, sendo este o crime que mais as encarcera, segundo INFOPEN 2017. Esses dados são, por ora, suficientes para compreendermos que o enfrentamento dos problemas causados pela política de drogas tem influência direta no debate do encarceramento em massa, pois ambos são pautados e construídos sobre alicerces ideológicos discriminatórios, racistas e classistas, os quais necessitam de um amplo debate e urgente remodelamento.

3.3 O cárcere no Brasil e sua composição sob o ponto de vista racial

A presente subseção não tem a intenção de ser longa e será montada de uma maneira diferente: apenas de dados. A análise realizada a partir do Levantamento Nacional de Informações Penitenciárias (INFOPEN), de 2017, e o Levantamento Nacional de Informações Penitenciárias (INFOPEN) Mulheres, de 2018, $2^{a}$ edição, ambos falam por si só.

Nosso sistema carcerário é composto por 726.712 mil presos. Destes, 64\% são negros, contra 32\% brancos; 55\% deles possuem entre 18 e 29 anos; 33,29\% são presos provisórios, ou seja, não foram condenados, enquanto 43,57\% cumpre regime fechado.

Em relação a taxa de ocupação no sistema prisional brasileiro, em junho de 2017, foi registrado uma taxa de 171,62\% de ocupação. 
Comparando-se os dados de dezembro de 2014 com os mais recentes, verifica-se um crescimento no déficit de vagas de 250.318 para mais de 300 mil vagas no país, estabelecendo que $89 \%$ dos presídios brasileiros estão com déficit de vagas.

Em Junho de 2016, a população prisional feminina atingiu a marca de 42 mil mulheres privadas de liberdade, o que representa um aumento de $656 \%$ em relação ao total registrado no início dos anos 2000 . Delas, 62\% são negras, de 18 a 29 anos (50\%), que não chegaram a completar o Ensino Fundamental (45\%).

Em termos internacionais, segundo o relatório, o Brasil é o terceiro país no mundo com maior número de pessoas presas. Tem menos presos que os Estados Unidos (2.145.100 presos) e a China (1.649.804 presos). Contudo, as taxas desses países vêm caindo ao longo dos anos, enquanto a do nosso país só tem aumentado.

Sendo assim, temos um resultado impassível de questionamento, pois o perfil do preso brasileiro é unanimemente: jovem, preto e pobre, evidenciando, assim, que o cárcere é a maior expressão do racismo na atualidade.

\section{A CONTRIBUIÇÃO DA CRIMINOLOGIA CRÍTICA PARA DETERMINAR A RELAÇÃO ENTRE RAÇA VS. ESTIGMA DE CRIMINOSO}

Como observamos, o nascimento da Criminologia e as teorias sobre a criminalidade foram um exemplo evidente de racismo, constituindo, em fins do século XIX, as falsas ideias científicas sobre a inferioridade racial. Falsas ideias pois, do século seguinte em diante, tais métodos passaram a ser questionados e, consequentemente, modificados. A teoria do "labbeling aproach" ou "teoria do etiquetamento" opõe-se, em 1960, à formação da pesquisa e do sistema penal vigente, passando a focar não mais no desviante, e sim em quem o criminaliza, conforme leciona a professora Vera Regina de Andrade (1995, p.28):

(...) o labelling parte dos conceitos de "conduta desviada" e "reação social", como termos reciprocamente interdependentes, para formular sua tese central: a de que o desvio e a criminalidade não é uma qualidade intrínseca da conduta ou uma entidade ontológica preconstituída à reação social e penal, mas uma qualidade (etiqueta) atribuída a determinados sujeitos através de complexos processos de interação social; isto é, de processos formais e 
informais de definição e seleção. (...) A criminalidade se revela, principalmente, como um status atribuído a determinados indivíduos mediante um duplo processo: a "definição" legal de crime, que atribui à conduta o caráter criminal e a "seleção" que etiqueta e estigmatiza um autor como criminoso entre todos aqueles que praticam tais condutas.

Assim, compreendemos que o sistema penal não se trata apenas do cumprimento da norma positivada, mas possui uma composição primária (Legislador) e secundária (Justiça) de criminalização, complementando o conceito de racismo institucional. A teoria do etiquetamento foi responsável por apontar que tais composições não podem ser vistas isoladamente, pois explicitam o funcionamento do sistema como um todo. Esta teoria nasce das denúncias e da necessidade de questionar a seletividade no sistema criminal, sua violência institucional, o encarceramento em massa, a vigilância policial nas periferias, o genocídio da população negra, entre outros, passando a tematizar tais questionamentos.

Ao contrário do que ocorria anteriormente [Escola Positivista], o uso da raça pelos agentes públicos para a identificação de criminosos é denunciado como uma dimensão do racismo, um aspecto da seletividade desse sistema. Os conceitos de vulnerabilidade e seletividade passam a ser decisivos. Os negros e indígenas não seriam mais criminosos, mas seriam mais vulneráveis diante da ação seletiva dos agentes do sistema de justiça criminal.

Hoje, a criminologia crítica busca reparar o erro da ciência perpetuado pela academia, evidenciando, através de intelectuais, que a presença de grupos vulneráveis, como os negros e indígenas, em ambientes universitários e acadêmicos, é de extrema necessidade para se contrapor com a branquitude detentora desde sempre dos meios científicos, jurídicos, entre outros no país que, impedidas pelo desconforto que a discussão sobre questões raciais pode trazer, de abordar tais temas, negligenciou-o por decisivas décadas (CARVALHO, 2003).

\section{5}

\section{CONCLUSÃO}

Conforme o exposto, apesar dos grandes avanços nas questões raciais, a sociedade brasileira continua a reproduzir os reflexos estruturais do racismo, fruto de quase quatro séculos de escravidão em nosso país. $\mathrm{Na}$ 
tentativa de criar uma identidade nacional, importamos conceitos e hábitos europeus, dentre deles, a nociva teoria do "deliquente nato", fazendo com que os estudiosos nacionais concluíssem que o Brasil deveria trilhar o caminho da Antropologia Criminal de Cesare Lombroso.

Tal teoria acrescida do mito da democracia racial, tomada como verdade universal pelo organismo social brasileiro, ocasionou uma negação e descaso social frente ao debate racial, por sua vez, necessário para o entendimento sobre qualquer questão a ser abordada no país. Afinal, está mais que claro que o fator racial é um basilar de nosso território.

Ademais, é possível positivar que a prisão e o sistema prisional, não nasceram repentinamente, mas gradativamente, sendo o sistema aprimorado com personas diversas, partindo da ideia central e única de limitação dos espaços físicos, de regras correcionais para certos e determinados grupos sociais, dando sentido ao processo de criminalização da pobreza fomentado pelo racismo institucional. Ambos continuam a liderar atuais discursos e debates, acerca da garantia de políticas públicas, visto tratarem-se de pessoas duplamente vulneráveis socialmente: negros e pobres, as maiores heranças da escravidão.

Hoje, com nossa Constituição democrática, a maior possibilidade mobilidade social, a maior presença de pessoas negras nas academias, ao questionamento da do mito da democracia racial e outros fatores, passouse a democratizar certas narrativas e espaços homogeneamente brancos. Apesar de possuirmos algumas medidas implantadas, como as ações afirmativas, a quantidade de corpos negros em tais lugares é deveras reduzida perante a enorme demanda acerca da questão que acumula séculos de explorações e negligência.

Entendemos como urgente a necessidade da criação de leis constitucionais e ordinárias de natureza redistributiva e cultural, pois um povo que conhece sua história e, consequentemente, se conhece, está cada vez mais distante de repetir erros ou reproduzir desigualdades.

\section{REFERÊNCIAS BIBLIOGRÁFICAS}

ARAÚJO, Joel Zito. A negação do Brasil. Brasil: 2000.

ALMEIDA, Silvio. Racismo estrutural. São Paulo: Sueli Carneiro; Pólen, 2019.

ANDRADE, Vera Regina Pereira de. Do paradigma etiológico ao paradigma da reação social: mudança e permanência de paradigmas criminológicos na ciência e no senso comum. Seqüência, 
BORGES, Juliana. Encarceramento em massa. São Paulo: Sueli Carneiro; Pólen, 2019.

BRASIL. Lei $n^{\circ} 8.072$, de 25 de julho de 1990. Dispõe sobre os crimes hediondos, nos termos do art. $5^{\circ}$, inciso XLIII, da Constituição Federal, e determina outras providências. Disponível em: http://www.planalto.gov.br/ccivil_03/LEIS/L8072.htm Acesso: 11 jul. 2019.

BRASIL. Lei n ${ }^{\circ} 11.343$, de 23 de agosto de 2006. Institui o Sistema Nacional de Políticas Públicas sobre Drogas - Sisnad; prescreve medidas para prevenção do uso indevido, atenção e reinserção social de usuários e dependentes de drogas; estabelece normas para repressão à produção não autorizada e ao tráfico ilícito de drogas; define crimes e dá outras providências. Disponível em: http://www.planalto.gov.br/ccivil_03/_Ato2004-2006/2006/Lei/L11343.htm Acesso em: 10 jul. 2019.

CARVALHO, José Jorge de. Ações afirmativas como resposta ao racismo acadêmico e seu impacto nas ciências sociais brasileiras. Teoria e Pesquisa 42 e 43, janeiro-julho, 2003, p.303-340.

LOMBROSO, Cesare. O homem delinqüente; tradução Sebastião José Roque. São Paulo:

MUNANGA, Kabengele. Rediscutindo a mestiçagem no Brasil: identidade nacional versus identidade negra. Petrópolis, RJ: Vozes, 1999.

SCHUCMAN, Lia Vainer. Entre o "encardido, o "branco e o "branquíssimo": raça, hierarquia e poder na construção da branquitude paulistana. Dissertação de Mestrado, São Paulo: Instituto de Psicicologia da Universidade de São Paulo, 2012.

SHIMIZU, Bruno; CACICEDO, Patrick. Crítica à estipulação de critérios quantitativos objetivos para diferenciação entre traficantes e usuários de drogas: reflexões a partir da perversidade do sistema penal em uma realidade marginal. Boletim IBCCRIM, São Paulo, v. 24, n. 286, p. 08-09., set. 2016. Disponível em: http://201.23.85.222/biblioteca/index.asp?codigo_sophia=131190. Acesso em: 26 ago. 2019.

UFSC, Florianópolis, SC, Brasil, V. 16, n. 30, p.24-36, jun. 1995. Disponível em:

https://periodicos.ufsc.br/index.php/sequencia/article/view/15819 Acesso em: nov. 2018.

ZACCONE, Orlando. Sistema penal e seletividade punitiva no tráfico de drogas ilícitas. Discursos Sediciosos: crime, direito e sociedade, Rio de Janeiro, n. 14, p. 181-198., anual. 2004. Disponível em: http://201.23.85.222/biblioteca/index.asp?codigo_sophia=65339. Acesso em: 10 ago. 2019. 